\title{
Anticipatory maternal effects in two different clones of Daphnia magna in response to food shortage
}

\author{
Gessica GORBI*, Fernanda MORONI, Sandra SEI and Valeria ROSSI \\ Department of Environmental Sciences, University of Parma, Viale G.P. Usberti 11/a, 43100 Parma, Italy \\ *e-mail corresponding author: gessica.gorbi@unipr.it
}

\begin{abstract}
The effects of food shortage on growth, fecundity, male production and offspring size and starvation tolerance in two different clones of Daphnia magna (Clone L and Clone P) were evaluated by disentangling the effects of resource depletion and crowding per se. Three experimental conditions were tested: high food - low daphnid density (the optimum), low food - low daphnid density and high food - high daphnid density. In the two first conditions, daphnids experienced the same population density but they had different food availability. In the two latter conditions, daphnids had the same per capita, low, food availability but they lived at different algae and daphnid densities. Moreover, the response of crowded females to recovery at high food availability and low population density was evaluated. Low food availability reduced growth and fecundity of both clones and increased male production only in the Clone L. Crowding per se did not affect growth but reduced fecundity. In both clones, low food availability due to low algae density enhanced investment in offspring size and resistance to starvation. In response to food shortage either due to low algae density and to crowding, Clone P increased the investment in offspring size and starvation tolerance but reduced fecundity to a lesser extent than Clone $L$ and did not produce males. Clone L, in response to food shortage due to crowding at high algae density, increased development time, produced more males, as at low algae density, but halved fecundity producing offspring that were not starvationtolerant. These results might reflect differences in anticipatory maternal effects between clones and suggest that neonate quality varies according to either, the environment the mother experienced and the competitive environment the neonates will cope due to their mother life strategy.
\end{abstract}

Key words: population density, crowding, environmental predictability, offspring size, resistance to starvation, genotype by environment interaction

\section{INTRODUCTION}

Population dynamics of zooplankton may be patchy in space and time and generally shows the characteristics of $r$-selected species: short generation time, rapid rates of expansion, especially in parthenogenetic taxa, and high population density. Most cladocerans have the capability of rapid population growth so that dramatic fluctuations and decline in abundance are common (Lampert \& Schober 1980; Sommer et al. 1986; Gliwitz et al. 2004). Optimization of responses to stimuli (e.g., photoperiod and temperature), according to their predictive value about the incoming environment, should be selected but, especially in unpredictable habitat, strategy may be needed long before environmental cues change. Under rapid and unpredictable condition changes, when food resources become overexploited or food and environmental quality deteriorate, maternal allocation of resources can have profound implication for the production of offspring appropriate for the conditions that the progeny are expected to encounter. There are many examples, across a range of taxa, showing that mothers may regulate the phenotype of their offspring according to local conditions for maximizing their fitness (La Monatgne \& McCauley 2001; Marshall \& Uller 2007). In cladocerans, food availabil- ity and population density are factors inducing phenotypic plasticity, reproduction switch and dormant (ephippial) egg production (Hobaek \& Larsson 1990; Kleiven et al. 1992; Ban et al. 2009). The utilization of density dependent cues is essential in population dynamics control: high population density induces life strategy shift by intraspecific interaction and acts as proximate factor of incoming worse food conditions (Cleuvers et al. 1997).

A reduced availability of food during development can affect adult morphology, physiology, behaviour and either long term and short term fitness. In Daphnia, food shortage during juvenile development delays development time and reduces growth rate, body size and reproductive output later in life (Glazier \& Calow 1992; Hanazato 1996; Pietrzak et al. 2010). Likewise, limited food access in the adult stage diminishes reproductive output and may influence responses to stress in the progeny (Baird et al. 1989, 1991; Hanazato \& Hirokawa 2004; Mitchell \& Read 2005).

The trade-off between size and number of eggs or neonates has been regarded as one of the most important component of life history theory and most studies on the genus Daphnia analyzed the responses to food availability by considering algae density. In various Daphnia species, adult females are able to arrange offspring size in response to food availability. At low food levels, $D$. 
magna females produce few neonates having a carapace length or weight greater than the ones produced in large broods at high food levels (Smith 1963; Cowgill et al. 1985; Enserink et al. 1990; Boersma 1997a, b; Barata \& Baird 1998). Glazier (1992) reported interclonal variability probably due to differences in adult metabolic rate leading to a different rate of self-depletion of food. Tessier et al. (1983) found that larger neonates are able to withstand starvation for longer time than the smaller ones, however contrasting results were reported (Enserink et al. 1993). A similar trade-off between size and number of eggs was observed in D. pulicaria and $D$. hyalina, with neonates from low-food mothers being more resistant to starvation (Gliwicz \& Guisande 1992). In D. pulex, Taylor (1985) reported that egg mass was significantly greater at the lowest food level but, in the same species, several authors reported that egg/neonate mass and/or offspring size from high-food daphnids were significantly higher than from mothers at low-food (Lynch et al. 1986; Tessier \& Consolatti 1991; La Montaigne \& McCauley 2001). In D. galeata offspring were smallest at low food level and largest at intermediate food level (Boersma 1995).

Relatively few studies analyzed the response to food depletion caused by variation in daphnid density or crowding. In D. magna, females maintained at low stocking densities produced larger numbers of smaller neonates than female at higher densities (Cox et al. 1992; Naylor et al. 1992). In both studies, the authors concluded that maternal density, and hence available food ration, influenced both length and weight of neonates. Cleuvers et al. (1997) described similar effects in crowded D. magna not subjected to food limitation. Martínez-Jerónimo et al. (2000) observed that the increase in population density caused a reduction in offspring number per female; besides, maintaining volume per individual equal, the presence of more than one adult per container caused a lower fecundity with respect to daphnids grown individually. Negative interference on growth and fecundity induced by metabolic products released by daphnids has been reported in various species (Goser \& Ratte 1994; Burns 1995; Boersma et al. 1999). Burns (2000) observed that the effect was significant only in small-bodied species. Ban et al. (2009) suggested that physical interference between neighboring individuals affects growth and reproduction. Various Daphnia species responded to crowding (obtained with either high population density or conditioned water) by reducing feeding rate (Hayward \& Gallup 1976; Helgen 1987; Matveev 1993; Boersma et al. 1999). Even if unequivocal and contradictory results could be partially due to differences in food levels and culture conditions, the outcome of the relationship between food availability and offspring size/quality appears controversal.

Our aim was to disentangle the effects of resource depletion from the effects due to crowding per se, by manipulating algae and daphnid density independently. We evaluated the effect of food availability on various traits of life cycle (growth, fecundity, offspring size and resistance to starvation) and the response of crowded females to recovery at high food availability and low population density. The response of two genetically different clonal lineages of D. magna to different conditions of food availability and population density was analyzed. The clones we choose differed in the production of males and sexual eggs (Gorbi et al. 1991).

\section{MATERIAL AND METHODS}

Two clones of D. magna from our laboratory collection were used: Clone P, originally obtained from the Institute of Ecosystem Study, CNR, Verbania Pallanza, (Italy) and Clone L, obtained from the University of Lyon (France). Each clone was identified and classified by the analysis of 14 polymorphic enzymes (unpublished data) and interclonal variation in three enzyme markers (GPI, 6PGD and GOT). The maintenance of the electrophoretic patterns was checked through two years. Previous studies demonstrated that these two clones differ in various life history traits (Gorbi et al. 1991).

To obtain the experimental cohorts, newborn females (about 40 for each clone) from mass cultures (reared at $20 \pm 1{ }^{\circ} \mathrm{C}$ and 12:12 L:D photoperiod in a climate-controlled chamber) were transferred to beakers containing $500 \mathrm{ml}$ mineral water $(\mathrm{pH}=7.45$; conductivity $419 \mu \mathrm{S} \mathrm{cm}^{-1}$; hardness $200 \mathrm{mg} \mathrm{CaCO} \mathrm{L}^{-1} ; 1 \mu \mathrm{g}$ B12 vitamin $\mathrm{L}^{-1}$ ) at 1 daphnid per $100 \mathrm{~mL}$ density and fed the freshwater green alga Scenedesmus acutus at $1.2 \times 10^{5}$ cells $\mathrm{mL}^{-1}$ density for at least 15 days. Water and food were renewed three times a week. Neonates (age $<24 \mathrm{~h}$ ) from the 4th clutch of these acclimated females were randomly assigned to beakers ( 5 individuals per batch) containing mineral water and were reared at three different experimental conditions: high algae density and low daphnid density (HALD), low algae density and low daphnid density (LALD), high algae density and high daphnid density (HAHD) (Tab. 1). In HALD treatment, daphnids were not crowded and not food limited, they were reared in the optimal conditions. In LALD treatment daphnids were not crowded but were food limited while, in HAHD treatment, daphnids were crowded and food limited. In HALD and HAHD treatments, daphnids were maintained at the same algae density but they had different per-capita food availability (HALD > HAHD). In HALD and LALD, daphnids experienced the same population density but they had different food availability (HALD > LALD). In HAHD and LALD, daphnids had the same per capita, low, food availability but they lived at different algae and daphnids densities (HAHD > LALD).

The experimental plan was as follows: 2 clones $\times 3$ treatments $\times 5-6$ replicates $\times 5$ daphnids per replicate. Water and food were renewed three times a week. Whenever a daphnid died, the volume in the vessel was 
Tab. 1. Experimental conditions: HALD $=$ high algae density and low daphnid density; LALD $=$ low algae density and low daphnid density; HAHD= high algae density and high daphnid density; HASD= stepped-up daphnids, i.e. transferred, on the $36^{\text {th }}$ day, from HAHD treatment to very high algae density and low daphnid density conditions. $\mathrm{C}=$ algae carbon content; $\mathrm{dw}=$ algae dry weight.

\begin{tabular}{lcccccc}
\hline Treatment & cells mL & $\mathrm{mg} \mathrm{dw} \mathrm{L}^{-1}$ & $\mathrm{mg} \mathrm{C} \mathrm{L}^{-1}$ & daphnids $100 \mathrm{~mL}^{-1}$ & $\mathrm{mg} \mathrm{dw}$ per capita & $\mathrm{mg} \mathrm{C}$ per capita \\
\hline HALD & $1.20 \times 10^{5}$ & 5.14 & 2.20 & 1 & $0.514 \pm 0.040$ & 0.220 \\
LALD & $0.24 \times 10^{5}$ & 1.03 & 0.44 & 1 & $0.103 \pm 0.008$ & 0.044 \\
HAHD & $1.20 \times 10^{5}$ & 5.14 & 2.20 & 5 & $0.103 \pm 0.008$ & 0.044 \\
HASD & $1.50 \times 10^{5}$ & 6.43 & 2.76 & 1 & $0.643 \pm 0.040$ & 0.276 \\
\hline
\end{tabular}
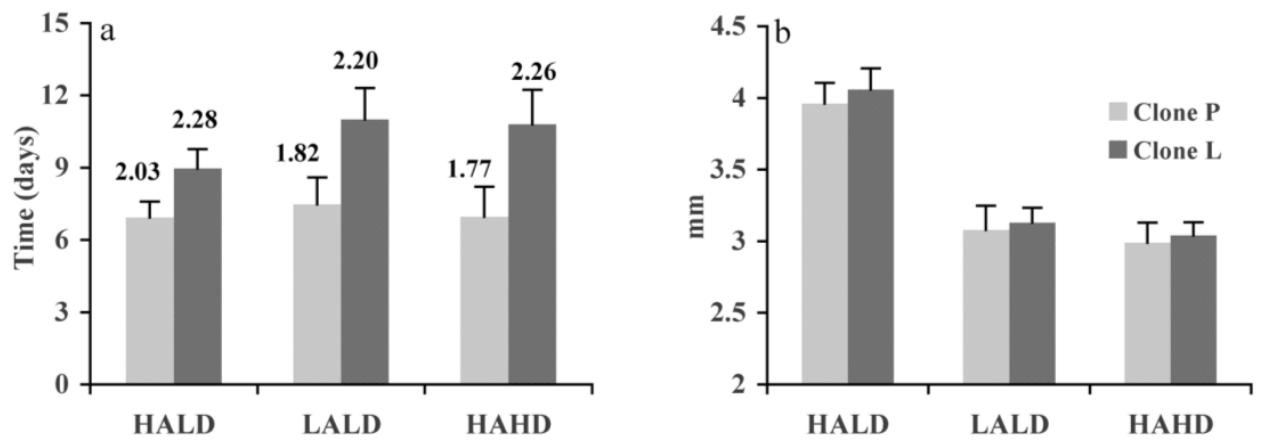

Fig. 1. (a) Mean age at maturity $( \pm \mathrm{sd})$ and (b) mean length on the $36^{\text {th }}$ day $( \pm \mathrm{sd})$ of Clone $\mathrm{P}$ and Clone $\mathrm{L}$ grown at different population density and food availability: high algae density and low daphnid density (HALD), low algae density and low daphnid density (LALD), high algae density and high daphnid density (HAHD). In graph (a) numbers correspond to the mean length at maturity $(\mathrm{mm})$.

proportionally reduced to maintain constant per capita food availability and population density. All experiments were carried out at $20 \pm 1{ }^{\circ} \mathrm{C}$ and 12:12 L:D photoperiod.

Daphnid growth, survival and fecundity were checked until the $36^{\text {th }}$ day. Growth was checked by measuring carapace length (with a time step of 5-8 days) of each daphnid from the upper edge to the base of the tail spine. Body size and gender of the neonates were recorded and their ability to withstand starvation was evaluated. For this purpose, 25-30 neonates (age $<24 \mathrm{~h})$ per treatment were reared in filtered $(0.45 \mu \mathrm{m}$ mesh) mineral water without food. Survival was checked daily and mean age at death was considered as neonate resistance to starvation.

To evaluate the effect of recovery from crowding on reproduction, a random sample of 36 days old daphnids from HAHD treatment (three batches per treatment) were transferred to a new experimental condition (HASD) where daphnids were neither crowded nor food limited (Tab. 1). Daphnid growth, survival and fecundity were checked until the $63^{\text {rd }}$ day and neonate body size and gender were recorded. For comparison, the remnant 36 days old daphnids, reared either at HALD and HAHD treatment (three batches per treatment), were maintained in their experimental conditions and checked until the $63^{\text {rd }}$ day.

The effect of different treatments on size, survival and fecundity of the two clones was tested using a twoway ANOVA. Within each clone, difference between treatments was tested using the Tukey test. Body size at maturity was estimated by linear regression of daphnid mean length from birth to 15 days age.

\section{RESULTS}

In all conditions, more than $90 \%$ of daphnids reached the reproduction age and more than $80 \%$ survived until the $36^{\text {th }}$ day.

In Clone $\mathrm{P}$, age at maturity did not change according to food ration and population density, while in Clone $\mathrm{L}$ it significantly increased with reduction of food availability and was not affected by crowding per se (HALD $<$ LALD = HAHD; $p<0.01$ ) (Fig. 1A; Tab. 2). In all conditions, Clone L took significantly longer time than Clone $\mathrm{P}$ to reach maturity $(p<0.001)$. Daphnid growth, from birth to 15 days age, was linear $\left(r^{2}\right.$ ranged from 1 to 0.952 ) and size at maturity, estimated by the linear regression, was greater in clone $\mathrm{L}$ in all tested conditions. In both clones, and particularly in Clone P, body size at maturity was lower in food-limited daphnids (Fig. 1A).

In both clones, growth was significantly reduced by food shortage (Fig. 1B): on the $36^{\text {th }}$ day, daphnid carapace length at high food level was greater than in foodlimited conditions (HALD $<$ LALD $=$ HAHD; $p<0.01$ ). Growth was not influenced by crowding per se since difference in mean daphnid size between LALD and HAHD treatments was not significant. At high food level (HALD), daphnids of Clone $\mathrm{L}$ were larger than daphnids of Clone $\mathrm{P}(p<0.01)$, while in food-limited and in crowded conditions (LALD and HAHD) mean size did not vary between clones. 
Tab. 2. Differences in mean values of six traits tested by two-ways ANOVA between clones and among treatments.

\begin{tabular}{|c|c|c|c|c|c|c|c|c|}
\hline Source & SS & $d f$ & $F$ & $p$ & SS & $d f$ & $F$ & $p$ \\
\hline & \multicolumn{4}{|c|}{ Mean age at reproduction } & \multicolumn{4}{|c|}{ Carapace length at 36 days age } \\
\hline Treatment & 51.84 & 2 & 20.25 & 0.000 & 31.66 & 2 & 869.39 & 0.000 \\
\hline Clone & 421.58 & 1 & 329.38 & 0.000 & 0.15 & 1 & 8.36 & 0.004 \\
\hline Treatment $*$ clone & 28.28 & 2 & 11.05 & 0.000 & 0.02 & 2 & 0.44 & 0.642 \\
\hline \multirow[t]{2}{*}{ Error } & 213.75 & 167 & & & 2.77 & 152 & & \\
\hline & \multicolumn{4}{|c|}{ Fecundity } & \multicolumn{4}{|c|}{ Abortion rate } \\
\hline Treatment & 5.11 & 2 & 1429.14 & 0.000 & 0.18 & 2 & 18.42 & 0.000 \\
\hline Clone & 0.11 & 1 & 61.08 & 0.000 & 0.05 & 1 & 11.19 & 0.002 \\
\hline Treatment $*$ clone & 0.11 & 2 & 31.74 & 0.000 & 0.16 & 2 & 16.38 & 0.000 \\
\hline \multirow[t]{2}{*}{ Error } & 0.05 & 29 & & & 0.14 & 29 & & \\
\hline & \multicolumn{4}{|c|}{ Offspring size } & \multicolumn{4}{|c|}{ Neonate resistance to starvation } \\
\hline Treatment & 1.000 & 2 & 354.02 & 0.000 & 304.01 & 2 & 12.45 & 0.000 \\
\hline Clone & 0.061 & 1 & 43.37 & 0.000 & 59.84 & 1 & 4.90 & 0.030 \\
\hline Treatment $*$ clone & 0.002 & 2 & 0.87 & 0.421 & 116.41 & 2 & 4.77 & 0.011 \\
\hline Error & 1.017 & 719 & & & 891.41 & 173 & & \\
\hline
\end{tabular}
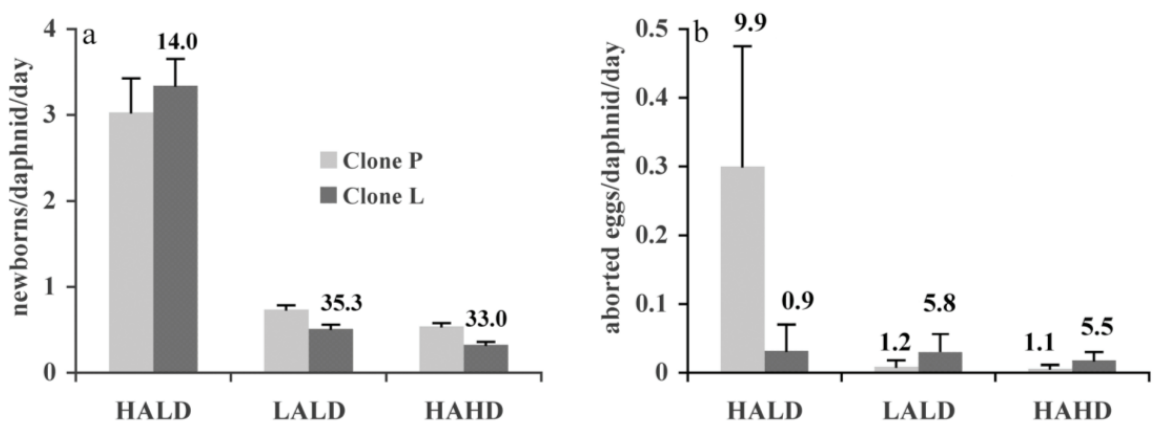

Fig. 2. (a) Fecundity (neonates per daphnid per day of survival \pm sd) and (b) abortion rate (aborted eggs per daphnid per day of survival $\pm \mathrm{sd}$ ) of Clone $\mathrm{P}$ and Clone $\mathrm{L}$ grown at different population density and food availability: high algae density and low daphnid density (HALD), low algae density and low daphnid density (LALD), high algae density and high daphnid density (HAHD). Numbers in graph (a) correspond to the percentage of male neonates in the progeny of Clone L; in Clone P no males were observed. Numbers in graph (b) correspond to the percentage of aborted eggs.

In both clones fecundity was reduced by food limitation and by crowding per se (HALD > LALD > HAHD, $p<0.001$ ) (Fig. 2A). At high food ration (HALD) fecundity was not different between clones, while at low algae density and in crowded conditions it was higher in Clone $\mathrm{P}$ than in Clone $\mathrm{L}(p<0.01)$, being almost twice in the HAHD condition. Fecundity slumped to $24 \%$ and $16 \%$, in Clone $\mathrm{P}$ and $\mathrm{L}$ respectively, when food shortage was due to low algae density, and to $17 \%$ and $9 \%$ when food limitation was due to crowding.

In Clone $\mathrm{P}$, abortion rate decreased with reduction of food availability and was not affected by crowding $($ HALD $>$ LALD $=$ HAHD, $p<0.01)$ ), so that percentage of aborted eggs was lower in food-limited conditions (Fig. 2B). In Clone L, abortion rate did not change following food shortage (HALD = LALD) and was only slightly reduced by crowding; as a consequence percentage of aborted eggs was higher in food-limited and crowded conditions. Abortion rate and percentage of aborted eggs in Clone $\mathrm{P}$ was higher than in Clone $\mathrm{L}$ at high food ration (HALD) and lower in food-limited conditions, either when food shortage was due to low algae density and to crowding.

Clone $\mathrm{P}$ did not produce males even in food limited and crowded conditions. Clone L produced males in all conditions (Fig. 2A): male percentage increased with reduction of food availability and was not influenced by crowding (HALD $<$ LALD $=$ HAHD; $p<0.05$ ).

In all conditions, offspring size in Clone $\mathrm{L}$ was significantly greater than in Clone P (Fig. 3A). In both clones, neonate size was larger at low food ration and was not influenced by crowding (HALD $<$ LALD $=$ HAHD, $p<0.01$ ). In Clone $\mathrm{P}$, neonates from food-limited mothers, either when food shortage was due to low algae density and to crowding, were able to survive starvation for longer time than neonates from mothers living at high food ration (HALD $<$ LALD $=$ HAHD, $p$ $<0.01$ ) (Fig. 3B). In Clone L, neonate resistance to starvation significantly increased only when food limitation in mother's environment was due to a low algae density $($ HALD $=$ HAHD $<$ LALD, $p<0.01)$.

A significant interaction between genotype and environment was observed in age at first deposition, fecun- 

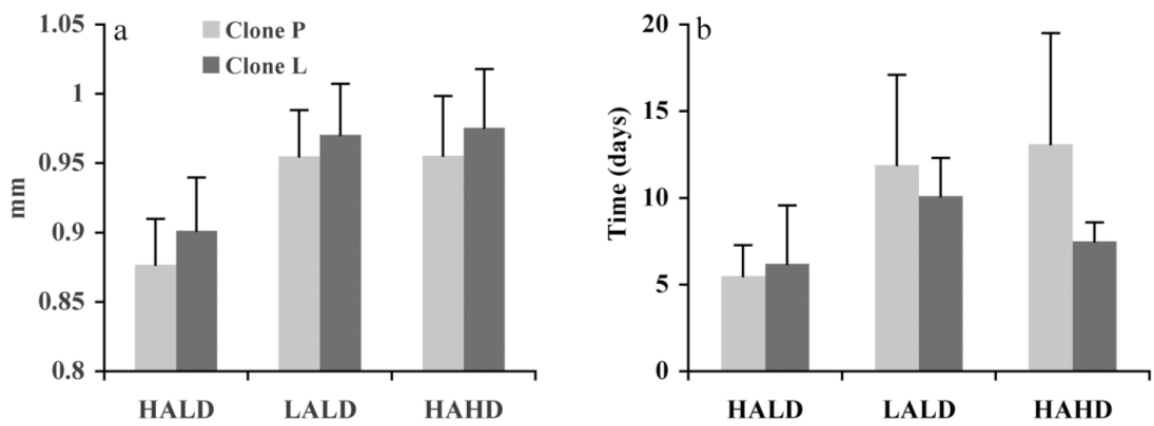

Fig. 3. (a) Mean length at birth ( \pm sd) and (b) mean age at death under starvation $( \pm \mathrm{sd})$ of neonates produced by Clone $\mathrm{P}$ and Clone $\mathrm{L}$ at different population density and food availability: high algae density and low daphnid density (HALD), low algae density and low daphnid density (LALD), high algae density and high daphnid density (HAHD).
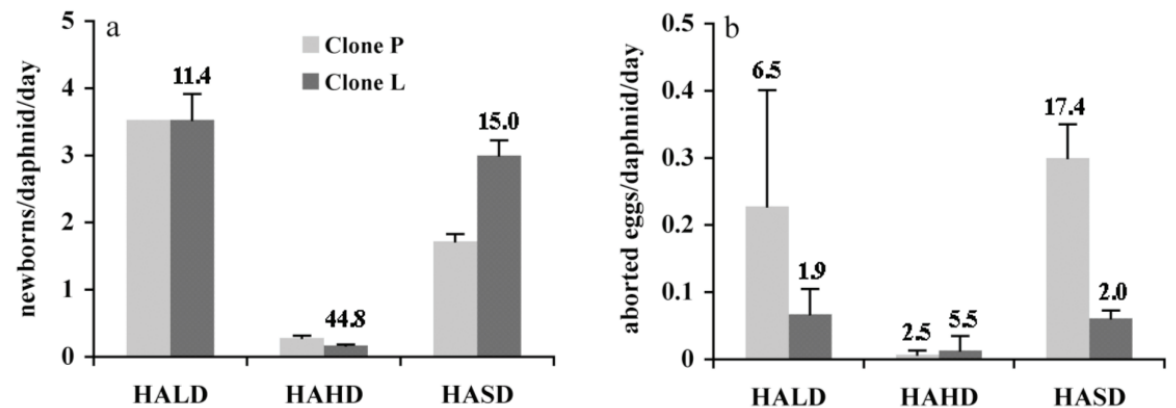

Fig. 4. (a) Fecundity (neonates per daphnid per day of survival \pm sd) and (b) abortion rate (aborted eggs per daphnid per day of survival $\pm \mathrm{sd}$ ) of Clone $\mathrm{P}$ and Clone L grown at different population density and food availability (high algae density and low daphnid density (HALD), high algae density and high daphnid density (HAHD)) and after transferring from high to low population density (stepped-up daphnids, HASD). Numbers in graph (a) correspond to the percentage of male neonates in the progeny of Clone L; in Clone P no males were observed. Numbers in graph (b) correspond to the percentage of aborted eggs.

dity, abortion rate and neonate resistance to starvation (two-way ANOVA, Tab. 2).

When 36 days old daphnids of both clones were transferred from crowded (HAHD treatment) to low population density and high food ration (stepped-up daphnids, HASD treatment), they increased growth rate and fecundity and produced smaller neonates. Growth rate increased to 0.022 and $0.030 \mathrm{~mm} \mathrm{day}^{-1}$, in Clone $\mathrm{P}$ and Clone $\mathrm{L}$ respectively, compared to 0.005 (Clone $\mathrm{P}$ ) and 0.004 (Clone L) $\mathrm{mm} \mathrm{day}^{-1}$ observed in daphnids maintained in crowded condition. In Clone L, fecundity completely recovered reaching a level similar to that of daphnids in HALD treatment; in Clone $\mathrm{P}$ it increased but remained at a significantly lower level (HALD > HASD; $p<0.001$ ) (Fig. 4A). After transferring, abortion rate increased in Clone $\mathrm{P}$ and decreased in Clone L (Fig. 4B). In Clone L, male percentage in the progeny decreased reaching a value similar to that observed in daphnids maintained at high food ration (HALD treatment) (Fig. 4A). In both clones, size at birth of neonates from stepped-up mothers (HASD) decreased to values observed in neonates from daphnids maintained at high food ration (HALD) and was significantly lower ( $p$ $<0.001)$ than that of neonates from crowded daphnids (HAHD) (Fig. 5).

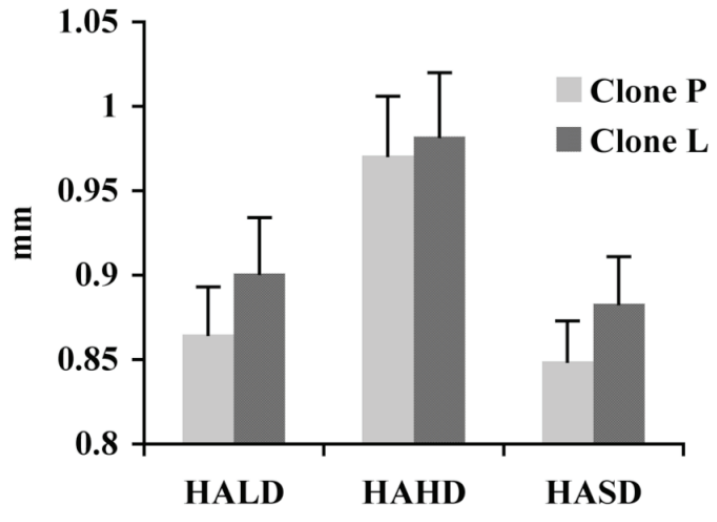

Fig. 5. Mean length at birth ( \pm sd) of neonates produced by daphnids of Clone $\mathrm{P}$ and Clone $\mathrm{L}$ reared at high algae density and low daphnid density (HALD), high algae density and high daphnid density (HAHD) and after transferring from crowded to not-crowded condition (stepped-up daphnids, HASD).

\section{DISCUSSION}

In our experiments, food limitation was obtained by reducing algae density (LALD) or by increasing daphnid density (HAHD). Since in both these treatments daphnids had the same per capita, low, food availabil- 
ity, comparison between LALD and HAHD treatments can account for effects of crowding per se.

As expected, low per capita food ration depressed growth and fecundity in both Daphnia magna clones: the effects of low food availability on reproduction might be mediated by a reduction in body size. In $D$. magna, age at maturity increases and size at maturity decreases when the environment becomes less favourable: the maturation size threshold could allow an optimal source allocation between growth and reproduction (Ebert 1994). Moreover, later onset of reproduction increases the probability that neonates will be born after the poor environment conditions have passed (Cleuvers et al. 1997). The effects on body size and age at reproduction seem to be different in cladocerans reared in food-limited or in crowded conditions. When food concentration is low, daphnids grow slowly and delay reproduction until the body reaches a certain size (Ebert 1991, 1994). By contrast, cladocerans in crowded condition with adequate food supply do not delay onset of reproduction but mature at smaller size than in non crowded conditions. Age at maturity did not vary in Clone $\mathrm{P}$ but increased in Clone L following food shortage. Consequently, differences in size at maturity between high- and low-food daphnids were more pronounced in Clone P than in Clone L. Age at maturity was not influenced by crowding per se, since no significant difference between LALD and HAHD conditions was observed.

The availability of adequate nutrition was the most important factor influencing fecundity in both clones. In food-limited conditions, higher age at maturity and higher percentages of aborted eggs were observed in Clone $\mathrm{L}$ with respect to Clone $\mathrm{P}$ and this fact contributed to Clone L lower fecundity. In both clones, crowding per se had a significant effect in reducing fecundity: being per capita food availability equal (0.103 mg per daphnid), fecundity was lower in HAHD than in LALD treatment. The effect of crowding on fecundity seems not mediated by size since, in both clones, mean body length was similar in HAHD and LALD conditions.

Food shortage caused the increase in male percentage in the progeny of Clone $\mathrm{L}$, while crowding per se had no impact, since the increment in HAHD and LALD with respect to HALD condition was the same. In D. magna, conflicting results on male production in response to food shortage and crowding (no male versus increasing male production) were reported by Cleuvers et al. (1997) and Hobaek \& Larsson (1990). Our data demonstrate that contrasting results may be due to interclonal differences. A significant interaction between clone and environment was also observed in mean age at reproduction, fecundity and neonate resistance to starvation, which shows that our two clones adopted a different life strategy in response to food availability and crowding. Inter genotype variation in reproductive responses to crowding has been also reported in $D . p u$ lex (Burns 2000; Fitzsimmons \& Innes 2006).

In our clones, low food availability due to low algae density (LALD treatment) reduced fecundity and enhanced offspring investment in terms of size and resistance to starvation. In order to anticipate food shortage in an environment where algae density was actually low, females of both clones produced larger and more starvation-tolerant offspring. Offspring size increased also when food shortage was due to crowding (HAHD treatment), but it was linked to the increase in resistance to starvation in Clone $\mathrm{P}$ and was not in Clone L. In HAHD treatment, algae density was high and the different strategy between the two clones in the investment in neonate resistance to starvation (despite the similar increase in size) might reflect different anticipatory maternal effects (sensu Marshall \& Uller 2007). Clonal mothers, according to the environment they experienced, perceived the probable environment that their neonates would cope and, as well in other life history traits, showed different strategies. In response to food shortage due either to low algae density (LALD treatment) and to crowding (HAHD treatment), Clone P greatly increased the investment in offspring capacity to survive starvation but reduced fecundity to a lesser extent than Clone $\mathrm{L}$ and did not produce any male. Clone $\mathrm{L}$, in response to food shortage due to crowding in presence of high algae density (HAHD), increased development time and produced more males, as it did in presence of food shortage caused by low algae density (LALD treatment), in addition it almost halved fecundity with respect to LALD treatment and to Clone P. This strategy implies a deeper reduction of population growth in Clone L than in Clone P. In an environment characterized by food shortage and high algae density, Clone L mothers did not change the investment in offspring capacity to survive starvation but arranged for a drastic reduction in population density, that is, for a less competitive environment for their offspring. These differences in strategy between clones could also be related to a proxy (high population and high algae density) that might be perceived as a condition having an unpredictable outcome. Actually, in presence of food limitation due to low algae density, both clones invested in a greater resistance to starvation in their progeny. Boersma et al. (1998) described inter-genotype difference among clones of D. magna in response to fish kairomones. Our results suggest that such differences can involve both responses to actual conditions and mother anticipatory behavior. It seems therefore that quality of neonates varies according to either the environment the mother experienced (per capita food ration, crowding and algae density) and the competitive environment the neonates will cope due to their mother's life strategy. Beckerman et al. (2006) suggested that, in Sancassania berlesei (a soil mite with limited dispersal capacity), maternal investment was significant but was a relatively 
small force compared to the progeny competitive environment created by mothers via size-number trade-off, that is controlling their offspring number. Larger neonates were produced during crowded treatment compared with not crowded treatment also in other cladoceran species (Ban et al. 2009). The production of large neonates by females that detect crowded situations would be advantageous for survival under forthcoming severe environmental food limitation (Cleuvers et al. 1997). Boersma (1997) suggested that, since daphnids live in changing environments with respect to food availability, adult females may use their resource acquisition as an estimate of the environmental conditions that their progeny will cope. Actually adult daphnids can rapidly (within two-three instars) modify their life strategy according to changes of food availability in their environment, as demonstrated by the behaviour of stepped-up daphnids in our experiments. Following the increase in food availability, mainly obtained by lowering population density, adult daphnids increased growth and fecundity and, above all, reduced size at birth of their offspring which were as small as the ones born from mothers grown at high food ration. A similar result was described by Enserink et al. (1993) in adult $D$. magna that experienced an increase in food availability due to the increase of algae density. According to McGinley et al. (1987), the manipulation of offspring size is favoured (adaptive) only when parents have the capability to drive their offspring for the incoming environmental conditions (i.e., into an appropriate habitat). Both clones in our experiments appeared to be able to change their strategy in accordance to changes in food availability and crowding. As reported by Cleuvers et al. (1997) in D. magna, life strategy shift by crowding, that is, by intraspecific interaction, might have an adaptive significance. In the field, the increase in grazing activity due to rapid cladoceran populations growth, can lead to a drastic drop in algae density. Over a short period of time, the fluctuation in food supply may even involve periods of starvation. In this situation it would be advantageous to produce a low number of bigger offspring having greater energy reserves and able to withstand starvation. This shift in life strategy may be triggered either, by intraspecific interaction and by food shortage, but the effect of intraspecific interaction can be effective before food deficiency actually occurs. Our results seem in accordance with this hypothesis since, in the presence of high algae density, crowded daphnids of both clones depressed fecundity to levels well below the per capita food ration could have sustained. In D. pulex, as well as in other taxa, the effect of crowding on reproduction seems caused by some physical interference between neighbouring individuals (Ban et al. 2009). It is well-known that many zooplankton species adopt patchiness or aggregation behaviour, forming swarms with a high density of individuals which benefit from a reduced predation rate but pay the cost of a greater intraspecific competition for food (Tessier 1983; Loose \& Dawidowics 1994). In this scenario, we can consider that aggregation behavior may be a sort of population regulation by intraspecific interaction, i.e. a typical $r$ selected species could benefit from a prompt density dependent regulation of population growth (Rossi et al. 2011).

In various species of the genus Daphnia, production of larger offspring has been observed when mothers were reared at low food ration compared to high-food mothers. Enserink et al. (1993) showed that the largest neonates, produced by D. magna at the lowest food level, accomplished a more rapid development during starvation. Even if they did not survive longer, they were able to reach the adolescent instar without any additional food and maintained their lead over smaller young during 21 days breeding, indicating that size at birth can have lasting influence. However a different behavior was reported in D. galeata (Boersma 1995) and in D. pulex (Lynch 1989; Tessier \& Consolatti 1991; La Montaigne \& McCauley 2001). Lynch (1989) observed that egg dry mass was lower when food carbon levels was reduced from $>1.5$ to $\leq 0.8 \mu \mathrm{g} \mathrm{mL} \mathrm{m}^{-1}$. Tessier \& Consolatti (1991) found that the lightest neonates were produced at the lowest food, but their size was not smaller than those of neonates produced at high food. La Montaigne \& McCauley (2001) reported that neonate size from high-food was significantly larger than for low-food mothers but there were no significant difference in resistance to starvation. By contrast, in the same species, Taylor (1985) reported that egg mass was significantly greater at the lowest food level and Ban et al. (2009) observed that, being constant food concentration, crowded daphnids produced larger and more starvation-tolerant offspring. If a greater size at birth can constitute an advantage, particularly when food is scarce, production of smaller or lighter neonate at low food rather than at high food ration appears a choice that needs further consideration.

\section{CONCLUSIONS}

Our results evidenced significant clonal differences in maternal anticipatory effect and this could improve population response to environmental unpredictability. Modulation of growth, fecundity, age at maturity and male production and the concomitant manipulation of offspring size/quality can be regarded as components of an unique complex strategy by which daphnids arrange either the environment of the progeny and offspring ability to withstand the incoming conditions. From this point of view, differences among clones and within species may also depend on differences in the trade-off among the various traits of maternal life strategy, i.e. a different balancing among the different traits.

Many zooplankton species form swarms with a high density of individuals that cope a great intraspecific competition for food. Our hypothesis is that this aggre- 
gation behaviour may be a mechanism of population regulation that even in a typical $r$-selected species could result in a prompt density dependent regulation of population dynamics.

\section{ACKNOWLEDGEMENTS}

The authors would like to thank the Italian Ministero dell'Istruzione dell'Università e della Ricerca (MIUR) for its financial support (PRIN 2007).

\section{REFERENCES}

Baird, D.J., I. Barber, M. Bradley, P. Calow \& A.M.V.M. Soares. 1989. The Daphnia bioassay: a critique. Hydrobiologia, 188/189: 403-406.

Baird, D.J., I. Barber, M. Bradley, A.M.V.M. Soares \& P. Calow. 1991. A comparative study of genotype sensitivity to acute toxic stress using clones of Daphnia magna Straus. Ecotoxicol. Environ. Safety, 21: 257-265.

Ban, S., H. Tenma, T. Mori \& K. Nishimura. 2009. Effects of physical interference on life history shifts in Daphnia pulex. J. Exp. Biol., 212: 3174-3183.

Barata, C. \& D.J. Baird. 1998. Phenotypic plasticity and constancy of life-history traits in laboratory clones of Daphnia magna Straus: effects of neonatal length. Funct. Ecol., 12: 442-452.

Beckerman, A.P., T.G. Benton, C.T. Lapsley \& N. Koesters. 2006. How effective are maternal effects at having effects? Proc. R. Soc. Lond. B, 273: 485-493.

Boersma, M. 1995. The allocation of resources to reproduction in Daphnia galeata: against the odds? Ecology, 76: 1251-1261.

Boersma, M. 1997a. Offspring size and parental fitness in Daphnia magna. Evol. Ecol., 11: 439-450.

Boersma, M. 1997b. Offspring size in Daphnia: does it pay to be overweight? Hydrobiologia, 360: 79-88.

Boersma, M., P. Spaak \& L. DeMeester. 1998. Predator-mediated plasticity in morphology, life history, and behavior of Daphnia: the uncoupling of responses. Am. Nat., 152: 237-248.

Boersma, M., L. DeMeester \& P. Spaak. 1999. Environmental stress and local adaptation in Daphnia magna. Limnol. Oceanogr., 44: 393-402.

Burns, C.W. 1995. Effects of crowding and different food levels on growth and reproductive investment of Daphnia. Oecologia, 101: 2334-244.

Burns, C.W. 2000. Crowding-induced changes in growth, reproduction and morphology of Daphnia. Freshwat. Biol., 43: 19-29.

Cleuvers, M., B. Goser \& H.T. Ratte. 1997. Life-strategy shift by intraspecific interaction in Daphnia magna: change in reproduction from quantity to quality. Oecologia, 110: 337-345.

Cowgill, U.M., D.L. Hopkins, S.L. Applegath, I.T. Takahashi, S.D. Brooks \& D.P. Milazzo. 1985. Brood size and neonate weight of Daphnia magna produced by nine diets. In: R.C. Bahner \& D.J. Hansen (Eds), Aquatic toxicology and hazard assessment. Eighth symposium ASTM STP 891, American Society for Testing and Materials, Philadelphia: 233-244.

Cox, E.J., C. Naylor, M.C. Bradley \& P. Calow. 1992. Effect of differing maternal ration on adult fecundity and offspring size in laboratory cultures of Daphnia magna Straus for ecotoxicological testing. Aquat. Toxicol., 24: 63-74.

Ebert, D. 1991. The effect of size at birth, maturation threshold and genetic differences on the life-history of Daphnia magna. Oecologia, 86: 243-250.

Ebert, D. 1994. A maturation size threshold and phenotypic plasticity of age and size at maturity in Daphnia magna. Oikos, 69: 309-317.
Enserink, L., M. de la Haye \& H. Maas. 1993. Reproductive strategy of Daphnia magna: implications for chronic toxicity tests. Aquat. Toxicol., 25: 111-123.

Enserink, L., W. Luttmer \& H. Maas-Diepeveen. 1990. Reproductive strategy of Daphnia magna affects the sensitivity of its progeny in acute toxicity tests. Aquat. Toxicol., 7: $15-25$.

Fitzsimmons, J.M. \& D.J. Innes. 2006. Inter-genotype variation in reproductive response to crowding among Daphnia pulex. Hydrobiologia, 568: 187-205.

Glazier, D.S. 1992. Effects of food, genotype, and maternal size and age on offspring investment in Daphnia magna. Ecology, 73: 910-926.

Glazier, D.S. \& P. Calow. 1992. Energy allocation rules in Daphnia magna: clonal and age differences in the effects of food limitation. Oecologia, 90: 540-549.

Gliwicz, Z.M. \& C. Guisande. 1992. Family planning in Daphnia: resistance to starvation in offspring born to mothers grown at different food levels. Oecologia, 91: 463-467.

Gliwicz, Z.M., A. Jawinski \& M. Pawłowicz. 2004. Cladoceran densities, day-to-day variability in food selection by smelt, and the birth-rate-compensation hypothesis. Hydrobiologia, 526: 171-186.

Gorbi, G., G.M. Paris, F. Moroni \& A. Bachiorri. 1991. Differences in population dynamics of Daphnia magna clones. Verh. Internat. Verein. Limnol., 24: 2809-2812.

Goser, B. \& H.T. Ratte. 1994. Experimental evidence of negative interference in Daphnia magna. Oecologia, 98: 354-361.

Hanazato, T. 1996. Combined effects of food shortage and oxygen deficiency on life history characteristics and filter screens of Daphnia. J. Plankton Res. 18: 757-765.

Hanazato, T. \& H. Hirokawa. 2004. Changes in vulnerability of Daphnia to an insecticide application depending on the population phase. Freshwat. Biol., 49: 402-409.

Hayward, R.S. \& D.N. Gallup. 1976. Feeding, filtering and assimilation in Daphnia schoedleri Sars as affected by environmental conditions. Arch. Hydrobiol., 77: 139-163.

Helgen, J.C. 1987. Feeding rate inhibition in crowded Daphnia pulex. Hydrobiologia, 154: 113-119.

Hobaek, A. \& A. Larsson. 1990. Sex determination in Daphnia magna. Ecology, 71: 2255-2268.

Kleiven, O.T., P. Larsson \& A. Hobaek. 1992. Sexual reproduction in Daphnia magna requires three stimuli. Oikos, 65: 197-206.

La Montagne, J.M. \& E. McCauley. 2001. Maternal effects in Daphnia: what mothers are telling their offspring and do they listen? Ecol. Lett., 4: 64-71.

Lampert, W. \& U. Schober. 1980. The importance of "threshold" food concentration. In: W.C. Kerfoot (Ed.), Evolution and Ecology, Zooplankton Communities. University Press of New England. Hanover. New Hampshire and London, England: 264-267.

Loose, C.J. \& P. Dawidowicz. 1994. Trade-offs in diel vertical migration by zooplankton: the cost of predator avoidance. Ecology, 75: 2255-2263.

Lynch, M. 1989. The life history consequences of resource depression in Daphnia pulex. Ecology, 70: 246-256.

Lynch, M., L.J. Wieder \& W. Lampert. 1986. Measurement of the carbon balance in Daphnia. Limnol. Oceanogr., 31: 17-33.

Marshall, D.J. \& T. Uller. 2007. When is a maternal effect adaptive? Oikos, 116: 1957-1963.

Martinez-Jeronimo, F., F. Espinosa-Chavez \& R. Villasenor. 2000. Effects of culture volume and adult density on the neonate production of Daphnia magna, as a test organism for aquatic toxicity tests. Environ. Toxicol., 15: 155-159.

Matveev, V. 1993. An investigation of allelopathic effects of Daphnia. Freshwat. Biol., 29: 99-105. 
McGinley, M.A., D.H. Temme \& M.A. Geber. 1987. Parental investment in offspring in variable environments: theoretical and empirical considerations. Am. Nat., 130: 370-398.

Mitchell, S.E. \& A.F. Read. 2005. Poor maternal environment enhances offspring disease resistance in an invertebrate? Proc. R. Soc. London B, 272: 2601-2607.

Naylor, C., E.J. Cox, M.C. Bradley \& P. Calow. 1992. Effect of differing maternal food ration on susceptibility of Daphnia magna Straus neonates to toxic substances. Aquat. Toxicol., 24: 75-82.

Pietrzak, B., M. Grzesiuk \& A. Bednarska. 2010. Food quantity shapes life history and survival strategies in Daphnia magna (Cladocera). Hydrobiologia, 643: 51-54.

Rossi, V., G. Benassi, F. Belletti \& P. Menozzi. 2011. Colonization, population dynamics, predatory behaviour and cannibalism in Heterocypris incongruens (Crustacea: Ostracoda). J. Limnol., 70(1): 102-108.

Received: February 2011

Accepted: March 2011
Smith, F.E. 1963. Population dynamics in Daphnia magna and a new model for population growth. Ecology, 44: 651-663.

Sommer, U., Z.M. Gliwicz, W. Lampert \& A. Duncan. 1986. The PEG model of seasonal succession of planktonic events in fresh waters. Arch. Hydrobiol., 106: 433-471.

Taylor, B.E. 1985. Effects of food limitation on growth and reproduction of Daphnia. Arch. Hydrobiol. Beih. Ergebn. Limnologie, 21: 285-296.

Tessier, A.J. 1983. Coherence and horizontal movements of patches of Holopedium gibberum (Cladocera). Oecologia, 60: 71-75.

Tessier, A.J. \& N. Consolatti. 1991. Resource quantity and offspring quality in Daphnia. Ecology, 72: 468-478.

Tessier, A.J., L.L. Henry, C.E. Goulden \& M.W. Durand. 1983. Starvation in Daphnia: energy reserves and reproductive allocation. Limnol. Oceanogr., 28: 667-676. 